\title{
How the brain processes violations of the grammatical norm: An fMRI study
}

\author{
Ferdy Hubers $^{\mathrm{a}, *}$, Tineke M. Snijders ${ }^{\mathrm{a}, \mathrm{b}}$, Helen de Hoop ${ }^{\mathrm{a}}$ \\ ${ }^{a}$ Centre for Language Studies, Radboud University, Erasmusplein 1, 6525 HT Nijmegen, The Netherlands \\ ${ }^{\mathrm{b}}$ Donders Centre for Cognitive Neuroimaging, Radboud University, Kapittelweg 29, 6525 EN Nijmegen, The Netherlands
}

\section{A R T I C L E I N F O}

\section{Article history:}

Received 12 January 2016

Revised 18 August 2016

Accepted 20 August 2016

\section{Keywords:}

Prescriptivism

Grammatical norm violations

Grammatical processing

Functional MRI

\begin{abstract}
A B S T R A C T
Native speakers of Dutch do not always adhere to prescriptive grammar rules in their daily speech. These grammatical norm violations can elicit emotional reactions in language purists, mostly high-educated people, who claim that for them these constructions are truly ungrammatical. However, linguists generally assume that grammatical norm violations are in fact truly grammatical, especially when they occur frequently in a language. In an fMRI study we investigated the processing of grammatical norm violations in the brains of language purists, and compared them with truly grammatical and truly ungrammatical sentences. Grammatical norm violations were found to be unique in that their processing resembled not only the processing of truly grammatical sentences (in left medial Superior Frontal Gyrus and Angular Gyrus), but also that of truly ungrammatical sentences (in Inferior Frontal Gyrus), despite what theories of grammar would usually lead us to believe.
\end{abstract}

(c) 2016 Elsevier Inc. All rights reserved.

\section{Introduction}

\subsection{Grammatical norm violations}

Considerable efforts are made in secondary education to teach students that some of their language forms are 'ungrammatical'. Despite these sustained efforts, the use of these constructions in everyday language would appear to be ineradicable. For example, it is quite common among native speakers of Dutch to use the pronoun hun 'them' as the subject of a sentence in daily speech (see (1a) for an example), even though prescriptive grammar prohibits it (van Bergen, Stoop, Vogels, \& de Hoop, 2011). Instead, the pronoun zij 'they' or ze 'they' should be used in this case (presented in (1b)).

(1)

a. Wat maken hun een vreselijk lawai.
what make them a terrible noise
"They are making a terrible noise."
What maken ze een vreselijk lawaai.
what make they a terrible noise

\footnotetext{
* Corresponding author.

E-mail addresses: f.hubers@let.ru.nl (F. Hubers), t.snijders@donders.ru.nl (T.M. Snijders), h.dehoop@let.ru.nl (H. de Hoop).
}

"They are making a terrible noise."

c. $\quad$ "Wat maken hem een vreselijk lawaai. what make him a terrible noise “*Him are making a terrible noise."

Although (1a) is commonly disapproved of by the majority of Dutch, it is frequently encountered, whereas (1c) which is 'truly ungrammatical' as indicated by the asterisk, is never encountered (compare the English translation, which is equally ungrammatical). Also, sentence (1a) is easily interpretable. This is supported by the fact that native speakers of Dutch, including the language purists who would not use this construction themselves, share the grammatical intuition that hun 'them' in (1a) can only refer to people (or animals), while its 'correct' counterpart ze 'they' in (1b) could also refer to machines or air planes (van Bergen et al., 2011). The truly ungrammatical variant in (1c) is hard to interpret, however, because it is unclear whether it is about a singular individual or a group of individuals.

Assuming that grammars are shaped by language use and processing, Hawkins (2004: 3) hypothesizes that "[g]rammars have conventionalized syntactic structures in proportion to their degree of preference in performance, as evidenced by patterns of selection in corpora and by ease of processing in psycholinguistic experiments". Grammatical norm violations are frequently used by native speakers, suggesting that they are part of grammar. How- 
ever, they are not frequently used by all native speakers of a language, because they are explicitly taught to be 'incorrect' or 'ungrammatical'. In theories of grammar, forms that are (sufficiently frequently) generated by language users are considered grammatical. Ungrammatical constructions are typically those that are never or hardly ever produced. For example, agreement errors such as ${ }^{*}$ The key to the cabinets were rusty are known to occur every now and then, but remain highly exceptional. Even in production experiments specifically designed to elicit these errors, they constitute at most 5\% of the responses (cf. Bock \& Miller, 1991; Veenstra, 2014). Moreover, native speakers generally share the intuition that such sentences are ungrammatical, as can be measured in grammaticality judgement tasks. Another example of a truly ungrammatical sentence in English would be *Who did a book about impress you? (Pinker, 1994: 87). Pinker (1994: 88) notes that such "sentences are 'ungrammatical', not in the sense of split infinitives, dangling participles, and the other hobgoblins of the schoolmarm, but in the sense that every ordinary speaker of the casual vernacular has a gut feeling that something is wrong with them, despite their interpretability".

Some truly ungrammatical sentences may indeed be interpretable, but this is not generally the case. However, violations of a grammatical norm (such as the 'split infinitives' in English mentioned by Pinker) are always perfectly interpretable within a language community (due to the fact that they are frequently encountered). This raises the question whether these violations of the grammatical norm are grammatical or ungrammatical. Violations of grammatical norms are crucially not considered ungrammatical by linguists, but they are often called 'ungrammatical' by language teachers and language purists. What are the consequences of this (un)grammaticality for processing? Some linguists have argued that the reason that some prescribed language forms are not acquired in a natural way (that is to say, they have to be explicitly taught) is because they are in fact ungrammatical. An example is the interrogative/relative object pronoun whom in English. Lasnik and Sobin (2000) argue that the form whom is not grammatical in present-day English, and that it is only used because it is required by prescriptive rules that "license normally unproducible prestige forms". This suggests that 'correct' language forms can be in conflict with the grammatical system (set of rules) of a language, and thereby in fact ungrammatical. By contrast, grammatical norm violations, which are frequently produced by native speakers of a language, are supposed to be in accordance with their internal grammatical system, hence grammatical. This is at least the view held by most linguists.

Another violation of the grammatical norm that frequently occurs in daily speech in Dutch is the use of the conjunction als 'as' in comparatives instead of the 'correct' form dan 'than' (as in Jan is groter dan Piet 'Jan is taller than Piet') (Hubers \& de Hoop, 2013). The use of als 'as' in comparatives is especially common among low-educated people (Hubers \& de Hoop, 2013) and in most dialects of Dutch (Barbiers, Bennis, de Vogelaer, Devos, \& van der Ham, 2005: 1.3.1.4). High-educated people often claim that for them grammatical norm violations are truly ungrammatical, but do they use these grammatical norm violations themselves? We conducted a corpus study in which we searched for the use of als 'as' in a comparative, and the use of subject hun 'them' as in (1a) in the Spoken Dutch Corpus (Oostdijk, 2000). This corpus consists of around 10 million spoken words and is divided into different components ranging from spontaneous face-to-face conversations to read speech. We found that only $5.2 \%$ of the 2697 higheducated individual speakers in the Spoken Dutch Corpus used als 'as' in comparatives as compared to $25 \%$ of the low-educated individual speakers. Almost $95 \%$ of the high-educated speakers in the corpus never used this grammatical norm violation at all. The pronoun hun 'them' as the subject of a sentence (as in (1a)) is even less frequently used: only $1.3 \%$ of the high-educated individual speakers in the corpus used this construction as compared to $22.9 \%$ of the low-educated speakers. Although almost none of the high-educated people use these grammatical norm violations themselves, they do understand these constructions perfectly well (and they may have used them in their childhood before they were taught not to use them).

When getting exposed to grammatical norm violations, an emotional reaction (e.g., repugnance) might be elicited among language purists. It is mainly because of these feelings that the language advisory council Genootschap Onze Taal 'Association of Our Language' advises not to use hun 'them' as the subject of a sentence:

"Veel mensen vinden een zin als Hun hebben dat gedaan zelfs verschrikkelijk [...]. Het is daarom het best het gebruik van hun als onderwerp te vermijden [...]."

"Many people find a sentence like Hun hebben dat gedaan 'Them have done it' horrible [...]. That is why it is recommended to avoid the use of hun 'them' as subject [...]."

[https://onzetaal.nl/taaladvies/advies/hun-hebben-zij-hebben]

Grammatical norm violations thus seem to differ from truly ungrammatical sentences. True ungrammaticalities are not frequently encountered in everyday speech and when they do, they do not seem to give rise to strong emotional reactions in people. By contrast, grammatical norm violations frequently occur in daily speech and seem to elicit strong emotional reactions in people. In addition, reading or hearing grammatically complex sentences and truly ungrammatical sentences generally lead to processing difficulties (Friederici, 2002; Friederici, Fiebach, Schlesewsky, Bornkessel, \& von Cramon, 2006; Friederici, Pfeifer, \& Hahne, 1993; Just, Carpenter, \& Woolley, 1982; Mitchell, 2004; Osterhout \& Holcomb, 1992), whereas for grammatical norm violations the results are rather mixed (Vos, 2015; Duffield, Matsuo, \& Roberts, 2007; Duffield, White, De Garavito, Montrul, \& Prévost, 2002). In a sentence matching experiment, Duffield et al. (2007) found that certain superficially ungrammatical sentences show a response latency similar to grammatical sentences and unlike truly ungrammatical sentences. They take this as evidence of the 'underlying' grammaticality of these constructions. However, in a sentence matching experiment on Dutch comparative sentences, Vos (2015) find two patterns of results. One group of participants read grammatical norm violations ('taller as') as fast as their truly grammatical counterparts ('taller than'), while their reading times for the truly ungrammatical sentences were significantly slower, which is in line with the findings of Duffield et al. (2002, 2007). However, for the other group of participants the reading times of grammatical norm violations patterned with the reading times of truly ungrammatical sentences and thus showed a processing slowdown. The different patterns of results may be due to their attitude towards grammatical norm violations, although this information was not available.

The present study seeks to answer two questions with respect to the processing of sentences containing grammatical norm violations. First, are these grammatical norm violations processed as truly grammatical sentences (as linguists would expect) or as truly ungrammatical sentences (as language purists who do not use these constructions themselves would probably expect)? Second, can we measure an emotional reaction in the brains of language purists when they encounter these grammatical norm violations? In order to be able to answer these two questions, we target the group of language purists, because these are the people who probably do not produce grammatical norm violations themselves, and who disapprove most strongly of the use of these constructions. Therefore, this is the group of speakers that may falsify the linguists' hypothesis that grammatical norm violations are in fact 
grammatical and thus will be treated in the brain as grammatical. Speakers who use grammatical norm violations in their everyday speech may not even be aware of the prescriptive rules, hence there is no reason to assume that they would process these constructions as if they were ungrammatical. Also, the language purists are the group of speakers that we expect to emotionally react to violations of the grammatical norm. If we do not find an emotional response to grammatical norm violations in the brains of language purists, then the chances are close to zero that we can find them elsewhere.

\subsection{Processing grammatical norm violations}

The apparent special status of grammatical norm violations leads to the question how this type of violation is processed in the brains of language purists, that is, people who have a good knowledge of the prescriptive grammar rules, apply these rules correctly, and who get upset when they encounter grammatical norm violations. Is the processing of grammatical norm violations comparable to the processing of truly grammatical or to the processing of ungrammatical sentences? Are additional brain regions involved that are usually associated with the processing of basic emotions or social cognition? These questions have received no attention so far in the neuroimaging literature.

During sentence processing a large network of perisylvian brain areas gets activated, mainly in the left hemisphere (Fedorenko \& Thompson-Schill, 2014; Friederici, 2002; Snijders et al., 2009). With regard to syntax processing the left Inferior Frontal Gyrus (LIFG, Broca's area) has received the most attention, with some researchers claiming syntax-specific operations in this brain area (e.g. Ben-Shachar, Hendler, Kahn, Ben-Bashat, \& Grodzinsky, 2003; Ben-Shachar, Palti, \& Grodzinsky, 2004; Embick, Marantz, Miyashita, O'Neil, \& Sakai, 2000; Santi \& Grodzinsky, 2007), while others have argued for a more domain-general role such as working-memory (Caplan, Alpert, Waters, \& Olivieri, 2000; Fiebach, Schlesewsky, Lohmann, von Cramon, \& Friederici, 2005), unification (Hagoort, 2005, 2016), selection (Thompson-Schill, 2005), or cognitive control (Bornkessel-Schlesewsky \& Schlesewsky, 2013) processes.

Ungrammaticalities are found to elicit increased activation in the left Inferior Frontal Gyrus (LIFG) as opposed to grammatical sentences (Embick et al., 2000; Friederici et al., 2006; Petersson, Forkstam, \& Ingvar, 2004). The question now is, whether the processing of grammatical norm violations elicits a similar activation in LIFG. If so, the LIFG activation to ungrammaticalities might not reflect syntactical processing per se, but instead more domaingeneral processes (e.g. unification/selection/cognitive control).

Besides comparing the processing of grammatical norm violations to that of correct and of truly ungrammatical sentences, in the current study we also compare it to processing of social norm violations (like 'jumping the queue') and basic emotions (disgust, contempt).

\subsection{The present study}

The present study aims to shed light on the processing of grammatical norm violations in the brain. On the one hand, we examined the processing of grammatical norm violations by investigating whether they are processed similarly to true ungrammaticalities or to truly grammatical sentences. On the other hand, we wanted to get insight in the emotional nature of grammatical norm violations. Metaphorically speaking, is it possible to measure an alarm bell that signals violations of a grammatical norm? That is, does the processing of grammatical norm violations elicit an emotional response (e.g., repugnance or disgust) in language purists, or is social cognition involved, as in the processing of sentences describing a socially unacceptable situation?

To this end, we set up an fMRI study in which we visually presented sentences containing grammatical norm violations as well as truly grammatical and truly ungrammatical sentences to people who are aware of the prescriptive grammar rules, apply them correctly and strongly reject violations of these rules. To see whether social cognition was involved in the processing of grammatical norm violations, we included sentences describing violations of social norms, so that we could compare the processing of these sentences with the processing of grammatical norm violations. In addition, as a localizer experiment, we presented participants with neutral, contemptuous and disgusted faces in order to see what brain regions were activated during the processing of these emotional faces, which allowed us to examine whether these brain regions are also involved in the processing of grammatical norm violations.

\section{Methods}

\subsection{Participants}

Participants were recruited via an online test, by which we were able to assess their knowledge of prescriptive grammar rules and their attitude towards grammatical norm violations. Participants were selected who judged at least thirty out of forty sentences correctly, i.e. in accordance with prescriptive grammar and spelling rules, and who scored at least a five out of seven on a scale measuring their annoyance towards so-called 'language errors', i.e., grammatical norm violations.

This resulted in thirty-one healthy volunteers, who participated in the fMRI study. One participant had to be excluded due to technical problems with the scanner. The remaining participants $(\mathrm{F}=18, \mathrm{M}=12)$ were right-handed native speakers of Dutch between thirty and fifty-one years old (mean age $=43.5$ ). They on average scored thirty-five out of forty sentences correctly in the recruitment test and indicated to get quite strongly annoyed when they encountered language errors (mean $=5.9$ out of 7 ). The participants had a normal or corrected-to-normal vision and hearing and no reported history of neurological or speech-language disorders. Prior to the experiment the participants signed an informed consent. They were paid afterwards. The experiment was approved by the local Ethical committee.

\subsection{Materials}

For the main experiment we created sentences that contained a grammatical norm violation (condition GN), a true ungrammaticality (condition UG) or no violation (condition GC). Five types of grammatical norm violations were included in the experiment, all of which frequently occur in Dutch, but are taught to be incorrect. Constructions were included in which 1 ) the pronoun hun 'them' was used as the subject, 2) als 'as' was used as a conjunction in comparative constructions, 3 ) an object pronoun was used after the conjunction dan 'than' or als 'as' in a comparative or equative construction, 4) the pronoun hun 'them' was used as the direct object and 5) the relative pronoun die 'that' was used with a neuter head noun. For each construction, thirty sentences were created. Three different versions were created out of each of these sentences, which resulted in 450 sentences in total. The first version contained a grammatical norm violation (condition GN, see example (1a)), the second version consisted of its prescriptively correct counterpart (condition GC, presented in (1b)) and the third version the truly ungrammatical counterpart (condition UG, see (1c)). 
No sentences consisted of more than twelve words and no words consisted of more than twelve letters. The critical word that differed between conditions was preceded by at least two words and followed by at least three words.

In order to compare the processing of grammatical norm violations with the processing of sentences describing social norm violations, ninety sets of social/semantic items were included. Each set consisted of three versions of the same sentence. The first version (condition SN) contained the description of a social norm violation (presented in (2a)). The second version (condition SC) consisted of its neutral counterpart (see (2b)) and the third version (condition SV) contained a semantic violation, which minimally differed from its counterparts (presented in (2c)).

(2)

a. De jongeman kruipt voor in de rij bij de kassa. $(\mathrm{SN})$

the young.man crawls ahead in the queue at the cash.register

"The young man jumps the queue at the cash register."

b. De jongeman sluit achteraan in de rij bij de kassa.

(SC)

the young.man shuts at.the.back in the queue at the cash.register

"The young man joins the queue at the cash register."

c. De jongeman kruipt onder in de rij bij de kassa. (SV)

the young.man crawls under in the queue at the cash.register

"The young man crawls under the queue at the cash register."
A semantic judgement task was conducted to examine whether the sentences containing a semantic violation would be perceived as semantically strange. Participants $(n=126)$ had to indicate on a likert scale from 1 to 5 whether the situation expressed by the sentence was likely to occur, in which ' 1 ' corresponded to 'highly improbable' and ' 5 ' to 'highly probable'. Neutral sentences (condition SC) and semantically anomalous sentences (condition SV) were included in this test. The neutral sentences had to receive a mean score of at least 4 and the semantically anomalous sentences had to receive a mean score of maximally 2 in order to be selected for the fMRI experiment. Sentences that did not meet these criteria were adjusted and tested again.

A social acceptability task was conducted in order to assess whether the sentences describing a social norm violation were perceived as a violation of the social norm. Participants $(n=122)$ were asked to indicate on a five point scale to what extent the situation described by the presented sentence was socially acceptable, in which ' 1 ' corresponded to 'socially unacceptable' and ' 5 ' to 'socially acceptable'. Sentences describing social norm violations (condition SN) as well as their neutral counterparts (condition SC) were included in the test. Sentences from condition SN had to receive a mean score of 2 or lower and sentences from condition SC had to receive a mean score of at least 4 in order to be selected for the experiment. Sentences that did not meet these criteria were adjusted and tested again.

For the emotion localizer experiment, neutral faces and faces expressing disgust and contempt were taken from the Radboud Faces Database (Langner et al., 2010). From the database we extracted sixteen Caucasian males and females. Each face occurred expressing all three emotions (neutral: Condition EN; contempt: Condition EC; disgust: Condition ED). They were presented with a frontal gaze direction. In total, ninety-six faces were included in the experiment. Arrows (to the left and to the right) were also included and were used as a baseline measurement.

\subsection{Design and procedure}

Each trial of the main experiment started with a fixation cross presented at the center of the screen for 2-6 s (randomly determined). Subsequently, a sentence was visually presented word by word on the center of the screen. Each word was depicted for $300 \mathrm{~ms}$, followed by a $200 \mathrm{~ms}$ presentation of a blank screen. Participants had to answer a comprehension question about the directly preceding sentence after every ten to fifteen sentences. This question required a 'yes'- or 'no'-response with a button box. Two breaks were included and the experiment started with a practice session. The main experiment took about $45 \mathrm{~min}$.

Three lists were created, containing 240 sentences (150 experimental items, 90 social/semantic items) and 26 questions. The three versions of each sentence were counterbalanced over the three lists. The sentences and questions were put in a pseudo randomized order using the software Mix (van Casteren \& Davis, 2006). After creating the lists three practice trials were added at the beginning of the lists.

For the localizer experiment a block design was used. The faces (half men, half women) and arrows (half left, half right) were presented in blocks of eight pictures. The procedure was taken from Sambataro et al. (2006) and slightly adapted. Each block of stimuli was preceded by a textual announcement of what type of block would be presented (PIJLEN 'arrows' or GEZICHTEN 'faces'). This announcement was shown for about $3 \mathrm{~s}$. Subsequently, a fixation cross was depicted on the center of the screen for $500 \mathrm{~ms}$, after which a picture was presented for $1500 \mathrm{~ms}$. When eight pictures were presented, a fixation cross and the textual announcement were presented again. Participants had to indicate the gender of the faces or the direction of the arrows, by pressing the corre- of the time. Sentences that did not meet these criteria were adjusted and tested again. 
sponding buttons on the button boxes. When the faces or arrows were presented, labels were depicted below the picture. In the case of faces, these labels indicated gender choices (left vrouw 'woman', right man 'man') and in case of arrows these labels indicated the pointing direction (left links 'left', right rechts 'right'). The localizer experiment took approximately $15 \mathrm{~min}$.

Three lists were created consisting of two practice blocks of each four pictures (first block: neutral faces, second block: arrows) and eighteen blocks of faces (emotion blocked: disgust, neutral, and contempt all 6 blocks) and seventeen blocks of arrows. The order of blocks, as well as the order of stimuli within each block (left/right and male/female) was pseudo randomized.

After the fMRI experiment the participants filled in a background questionnaire and a test in which they were asked to score a subset of sentences on a five points scale with respect to acceptability.

\section{4. fMRI data acquisition and statistical analysis}

During the presentation of the sentences (main experiment) and pictures (localizer experiment) the fMRI data were acquired with a SIEMENS MAGNETOM Skyra 3T MR scanner using an ascending slice acquisition sequence. A multi-echo EPI sequence was used in order to obtain 36 slices per volume (voxel size $=3.3 \times 3.3 \times 3.0 \mathrm{~mm}$; $\quad$ repetition time $(\mathrm{TR})=2250 \mathrm{~ms}$; $\mathrm{TE} 1=9.0 \mathrm{~ms}, \quad \mathrm{TE} 2=19.5 \mathrm{~ms}, \quad \mathrm{TE} 3=30.0 \mathrm{~ms}, \quad \mathrm{TE} 4=40.0 \mathrm{~ms} ; \quad$ flip angle $=90 \mathrm{deg}$; field of view $=212 \mathrm{~mm}$ ). In between the main and faces experiment a high-resolution anatomical scan was acquired (T1-weighted MPRAGE, voxel size $=1 \times 1 \times 1 \mathrm{~mm}$, TR $=2300 \mathrm{~ms}$, $\mathrm{TE}=3.03 \mathrm{~ms}, 192$ slices with thickness of $1 \mathrm{~mm}$, field of view $=256 \mathrm{~mm}$ ) accelerated with GRAPPA parallel imaging (Griswold et al., 2002).

The multi-echo DICOMs were combined with an ad hoc Matlab script, for which the weighting of the echoes was calculated based on the first 30 volumes obtained before the start of the actual experiment. The preprocessing was done using SPM 8 (www.fil. ion.ucl.ac.uk/spm) and consisted of the realignment of the combined data, co-registering the subject-mean images with respect to the corresponding structural scans and applying slice timing, in which the middle slice (slice 18) was taken as the reference slice. The data were normalised in Montreal Neurological Institute (MNI) space as defined by the EPI template of SPM and smoothing was applied (FWHM $=8.0 \mathrm{~mm}$ ).

Main experiment. The fMRI data were statistically analysed by using multiple regression at the subject level of analysis and flexible factorial regression at the second level or group level, as not all main effects had to be tested. In addition, this method automatically checked for sphericity of the data. Mini-block regressors were included in the regression analyses to model the sentence presentation from the onset of the critical word to the offset of the last word of the sentence. The presentation of the words preceding the critical word were modelled as regressors of no interest (OW, other words) and the presentation of the fixation cross (FIX) as an explicit baseline. Realignment parameters for movement were included to account for effects of no interest as well. Singlesubject contrast images were created by subtracting the regression parameter of the fixation cross from the regression parameters that were condition specific. In this way, contrast images were defined for GN (Grammatical norm violation), GC (Grammatical), UG (Ungrammatical), SN (Social norm violation), SC (Neutral), SV (Semantic violation) and OW (Other words). At the second level, flexible factorial whole-brain analyses were conducted on the contrasts created at the first level, including the factors condition (6) and subjects (30). To see whether norm specific effects were present in the processing of grammatical norm violations the following contrast was examined: grammatical norm $>$ grammatical exclusively masked with ungrammatical $>$ grammatical (uncorrected mask: $\mathrm{p}=0.05$ ). The contrasts grammatical norm $>$ grammatical inclusively masked with ungrammatical $>$ grammatical (uncorrected mask: $\mathrm{p}=0.05$ ) and grammatical norm $>$ ungrammatical inclusively masked with grammatical $>$ ungrammatical (uncorrected mask: $\mathrm{p}=0.05$ ) were examined in order to study the overlap between grammatical norm violations and truly grammatical and truly ungrammatical sentences. In order to investigate whether norm specific effects were present in the processing of social norm violations, we looked at the contrast social norm $>$ neutral exclusively masked with semantic violations $>$ neutral (uncorrected mask: $\mathrm{p}=0.05$ ). The overlap of social norm violations and neutral and semantically anomalous sentences were studied by examining the contrasts social norm $>$ semantic violations inclusively masked with neutral > semantic violation (uncorrected mask: $\mathrm{p}=0.05$ ) and social norm $>$ neutral inclusively masked with semantic violations $>$ neutral (uncorrected mask: $\mathrm{p}=0.05$ ). For all comparisons the cluster-size statistics were examined. Statistical inferences were made at the cluster level (cluster extent $\mathrm{P}>0.05$, corrected for multiple comparisons (Forman et al., 1995)).

Localizer experiment. For the localizer experiment, at the first level, the fMRI data were analysed using multiple regression. The presentations of the facial blocks, including the fixation crosses, were modelled as regressors. The presentations of the arrow blocks were treated as explicit baseline. Realignment parameters for movement were included to account for effects of no interest. Single-subject contrast images were created for the conditions EN (neutral emotion), EC (contempt), ED (disgust) relative to the baseline condition (arrows). At the second level, flexible factorial whole-brain analyses were conducted on the contrasts created at the first level, including the factors condition (3) and subjects (30). To see whether the amygdala and the insula were involved in the processing of basic emotions, the following contrasts were examined: contempt > neutral, disgust > neutral, disgust > neutral inclusively masked with contempt $>$ neutral (uncorrected mask: $\mathrm{p}=0.05$ ). SPMs were thresholded at $\mathrm{p}<0.001$ uncorrected at voxel level. To protect against false positive results, statistical inferences were made at the cluster level (cluster extent $\mathrm{P}>0.05$, corrected for multiple comparisons (Forman et al., 1995)).

Anatomical inference. All local maxima are reported as MNI coordinates (Evans et al., 1993). Relevant anatomical landmarks were identified using the Microscopic Atlas (Mai, Assheuer, \& Paxinos, 2004) and Brodmann areas were defined using MRIcron (Rorden, Karnath, \& Bonilha, 2007).

\section{Results}

\subsection{Accuracy}

The participants performed well on the main experiment task (mean number of errors: 2.33 out of 26), and on the faces task (mean number of errors: 3.03 out of 280) and therefore did not have to be excluded from the statistical analyses.

\section{2. fMRI results}

\subsubsection{Norm specific effects}

The whole-brain analyses revealed a norm specific effect for social norm violations, which is in line with the previous literature (Berthoz, Armony, Blair, \& Dolan, 2002; Prehn et al., 2008; Spitzer, Fischbacher, Herrnberger, Grön, \& Fehr, 2007). The left medial Superior Frontal Gyrus (LmSFG, BA 9, 32 and 10) was increasingly activated for social norm violations as opposed to neutral sentences and sentences containing a semantic violation (see Supplementary Table 1 and Supplementary Fig. 1). 
For grammatical norm violations, however, no regions were activated that were not active during the processing of truly grammatical or truly ungrammatical sentences. When directly comparing grammatical norm violations $(\mathrm{GN}>\mathrm{GC})$ with social norm violation $(\mathrm{SN}>\mathrm{SC})$ no regions were activated more for grammatical than for social norm violations, while LmSFG and left inferior/middle temporal Gyrus were activated more for social than for grammatical norm violations (see Supplementary Table and Fig. 6).

\subsubsection{Grammatical norm violations: overlap with truly grammatical} and ungrammatical sentences

The processing of grammatical norm violations overlapped with the processing of truly ungrammatical sentences, as can be seen in Table 1. The bilateral Inferior Frontal Gyrus and the bilateral Supplementary Motor Areas were increasingly activated during the processing of both grammatical norm violations and truly ungrammatical sentences, but not during the processing of truly grammatical sentences (see Supplementary Fig. 7 for averaged percent signal change in LIFG). This pattern of activation is visually presented in Fig. 1.

Interestingly, we also found brain regions activated similarly during both the processing of grammatical norm violations and truly grammatical sentences as opposed to truly ungrammatical sentences (see Table 2). The left Angular Gyrus and the left medial Superior Frontal Gyrus were involved in the processing of grammatical norm violations and the processing of truly grammatical sentences, more than for the processing of truly ungrammatical sentences (see Fig. 2). In both areas, a decrease in activation was observed for truly ungrammatical sentences whereas this was not the case for grammatical norm violations and grammatical sentences (see Supplementary Figs. 8 and 9). The results of the basic contrasts without masking (ungrammatical > grammatical, grammatical norm > grammatical) can be found in the Appendix (Supplementary Tables 4 and 5 ).

\subsubsection{Social norm violations: overlap with neutral and semantically anomalous sentences}

In order to be able to compare the processing of grammatical norm violations with the processing of social norm violations we examined whether overlap was present for social norm violations and neutral sentences and social norm violations and semantically anomalous sentences. We found no increased activation similar for the processing of social norm violations and the processing of semantically anomalous sentences as opposed to processing neutral sentences. However, during the processing of social norm violations brain regions were involved that were also activated during the processing of neutral sentences but not during the processing of semantic violations. Increased activation was found in the left Frontal brain regions, the bilateral Cingulate, the bilateral Middle Temporal Gyrus and the left Angular Gyrus (see Supplementary Table 2 and Supplementary Fig. 2).

On the one hand, the processing of social norm violations seems to be comparable to the processing of grammatical norm violations, in that all brain regions activated during the processing of grammatical norm violations and truly grammatical sentences (LmSFG and LAG) are also involved in the processing of both social norm violations and neutral sentences. On the other hand, no brain regions are commonly activated during the processing of social norm violations and semantic violations whereas for grammatical norm violations and truly ungrammatical sentences the LIFG is commonly involved (Table 1 ).

\subsubsection{Localizer}

In contrast to what we expected on the basis of the literature (Aleman \& Swart, 2008; Sambataro et al., 2006), no increased activation was found in the amygdala or insula during the processing of disgusted and contemptuous faces as compared to neutral faces. For disgusted faces, however, we did find increased activation in the Superior and Middle Temporal Gyrus and the left Middle Occipital Gyrus as compared to neutral faces (see Supplementary Table 3). The processing of contemptuous faces did not yield any significant differences as compared to neutral faces. Since we did not find activation in the amygdala and insula and the increased activation in the Temporal Gyrus was only specific to the processing of disgusted faces, but not to that of contemptuous faces, we had no reason based on the localizer to conduct an ROI analysis with respect to the processing of grammatical norm violations.

\section{Discussion}

In this study we investigated the processing of grammatical norm violations in the brain in order to address two questions: (i) are grammatical norm violations processed as truly grammatical sentences or are they processed as truly ungrammatical? (ii) Can we measure an emotional reaction in the brain when language purists encounter a grammatical norm violation? In line with theories of grammar, it was hypothesized that the processing of grammatical norm violations would be similar to the processing of truly grammatical sentences, even in the brains of language purists who themselves may call grammatical norm violations 'ungrammatical'. In addition, we expected to find brain regions activated during the processing of grammatical norm violations that are usually involved in the processing of basic emotions (e.g. repugnance or disgust) or social cognition.

Table 1

Overlap in processing of grammatical norm violations and ungrammatical sentences as compared to grammatical sentences.

\begin{tabular}{|c|c|c|c|c|c|c|}
\hline Region & $\mathrm{BA}$ & Cluster size & Voxel $\mathrm{T}^{100}$ value & $\mathrm{x}$ & $\mathrm{y}$ & $\mathrm{z}$ \\
\hline \multicolumn{7}{|c|}{ Grammatical norm > grammatical (incl. ungrammatical > grammatical) } \\
\hline L Inferior Frontal Gyrus & & 1122 & & & & \\
\hline L Superior Temporal Pole & 38 & & 6.59 & -52 & 14 & -4 \\
\hline L Inferior Frontal Gyrus (operculum) & 44 & & 5.67 & -50 & 10 & 6 \\
\hline L Inferior Frontal Gyrus (orbitalis) & 47 & & 5.65 & -46 & 24 & -2 \\
\hline Bilateral Supplementary Motor Area & & 461 & & & & \\
\hline R Supplementary Motor Area & 6 & & 5.36 & 8 & 16 & 66 \\
\hline L Supplementary Motor Area & 32 & & 3.94 & -6 & 18 & 48 \\
\hline L Supplementary Motor Area & 6 & & 3.61 & -8 & 12 & 56 \\
\hline R Inferior Frontal Gyrus/Insula & & 394 & & & & \\
\hline R Inferior Frontal Gyrus (triangularis) & 47 & & 4.80 & 44 & 26 & 0 \\
\hline R Inferior Frontal Gyrus (orbitalis) & 38 & & 4.66 & 50 & 20 & -8 \\
\hline R Insula & 48 & & 3.75 & 40 & 16 & -2 \\
\hline
\end{tabular}

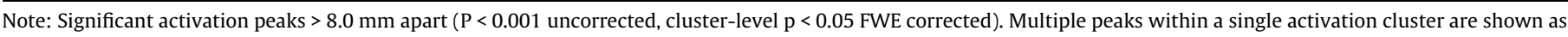
intended. 


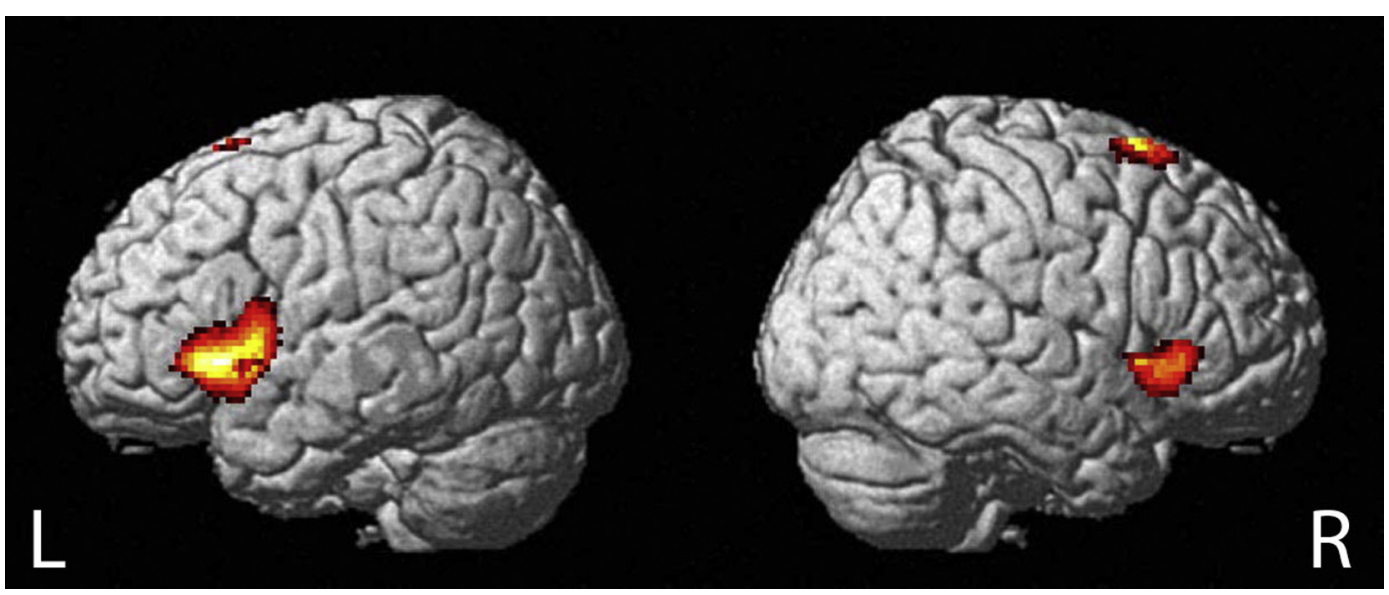

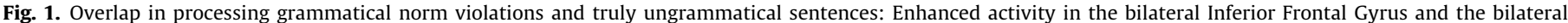

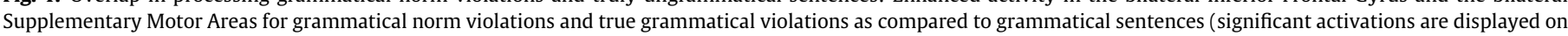
a rendered template of a brain, activations shown at voxel-level $\mathrm{P}_{\text {uncorr }}<0.001$, cluster-level $\mathrm{p}<0.05$ FWE corrected).

Table 2

Overlap in processing of grammatical norm violations and truly grammatical in contrast to truly ungrammatical sentences.

\begin{tabular}{|c|c|c|c|c|c|c|}
\hline Region & BA & Cluster size & Voxel $\mathrm{T}^{100}$ value & $\mathrm{X}$ & $\mathrm{y}$ & $\mathrm{z}$ \\
\hline \multicolumn{7}{|c|}{ Grammatical norm > ungrammatical (incl. grammatical > ungrammatical) } \\
\hline L medial Superior Frontal Gyrus & & 789 & & & & \\
\hline L medial Superior Frontal Gyrus & 10 & & 4.24 & -4 & 64 & 24 \\
\hline L medial Superior Frontal Gyrus & 9 & & 4.16 & 0 & 52 & 48 \\
\hline L medial Superior Frontal Gyrus & 8 & & 4.11 & -4 & 44 & 52 \\
\hline L Angular Gyrus & & 422 & & & & \\
\hline L Angular Gyrus & 39 & & 4.73 & -46 & -68 & 28 \\
\hline L Angular Gyrus & 39 & & 3.75 & -46 & -80 & 32 \\
\hline
\end{tabular}

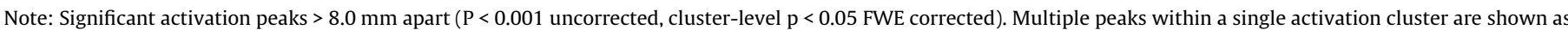
intended.

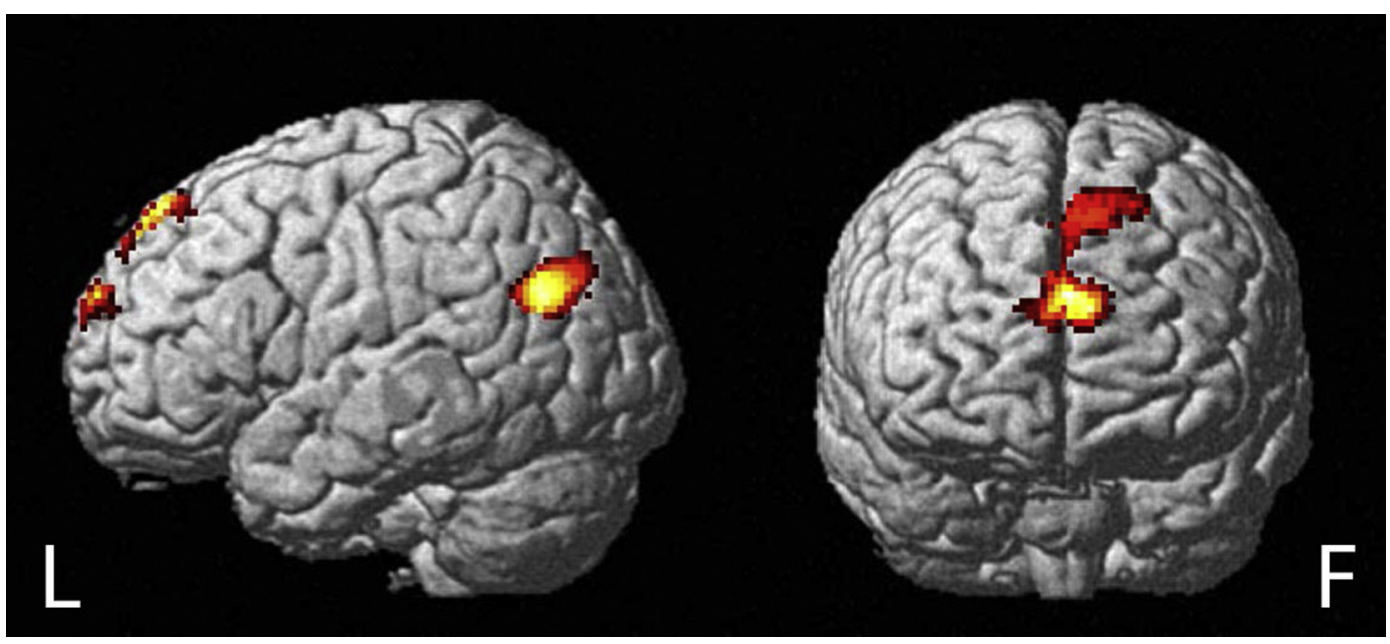

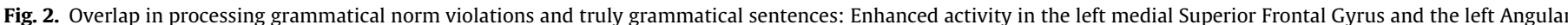

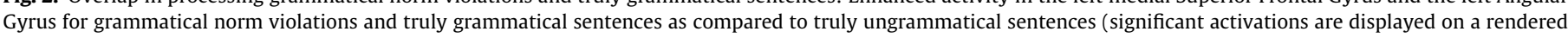
template of a brain, activations shown at voxel-level $\mathrm{P}_{\text {uncorr }}<0.001$, cluster-level $\mathrm{p}<0.05$ FWE corrected).

Both the processing of grammatical norm violations shows resemblance with the processing of grammatical sentences on the one hand and with the processing of truly ungrammatical sentences on the other. That is, both grammatical norm violations and ungrammatical sentences elicited more Inferior Frontal Gyrus (IFG) activation than grammatical sentences, while ungrammatical sentences showed a decrease in activation in the left medial Superior Frontal Gyrus (mSFG) and Angular Gyrus as opposed to both gram- matical norm violations and grammatical sentences. Even in this group of language purists no specific norm-related effects were elicited upon reading grammatical norm violations. Sentences describing social norm violations, however, did elicit normspecific effects, as was expected on the basis of the literature (Berthoz et al., 2002; Prehn et al., 2008; Spitzer et al., 2007). In addition, the processing of social norm violations overlapped with the processing of neutral sentences, but not with the processing of 
semantically anomalous sentences. The overlap between social norm violations and neutral sentences was quite similar to the overlap between grammatical norm violations and grammatical sentences. Yet, grammatical norm violations seemed to be different from social norm violations, in that for grammatical norm violations no specific norm-related effects were found and additionally overlap was present between grammatical norm violations and truly ungrammatical sentences, whereas no overlap was present between social norm violations and semantic violations.

No additional brain activation was found in the medial Superior Frontal Gyrus or in the insula or amygdala in response to grammatical norm violations, meaning we found no evidence for the involvement of brain regions implicated in social cognition (Berthoz et al., 2002; Prehn et al., 2008; Spitzer et al., 2007), or basic emotions like disgust or contempt (Aleman \& Swart, 2008; Sambataro et al., 2006), in the processing of these constructions. The lack of specific effects, however, might be due to the method of sentence presentation. People who experience emotions when they encounter grammatical norm violations, probably experience these emotions when they encounter them in their daily lives, e.g., when they hear their interlocutor use them or when they read them in a newspaper. The situation in the MRI scanner was quite unnatural, in that the grammatical norm violations were presented without further context in what the participants knew to be a language experiment. This unnatural situation might have prevented basic emotions and social cognition to be involved in response to the grammatical norm violations.

The lack of activation in the amygdala might also be due to a decreased reactivity in the amygdala towards negative emotions as people get older (Gunning-Dixon et al., 2003; Iidaka et al., 2002; Mather et al., 2004). Mather et al. (2004) found that for older adults, seeing positive pictures led to greater amygdala activation than seeing negative pictures, whereas for younger adults the activation in the amygdala was the same for positive and negative emotional pictures. This, in combination with the fact that we did not find an increased amygdala activation in our localizer task for the processing of disgusted and contemptuous faces as compared to neutral faces, might be another reason why we did not find the amygdala to be involved in the processing of grammatical norm violations in this population.

While no specific effects were found in the processing of grammatical norm violations, this study has revealed that these constructions are nevertheless unique, since they seem to be partly similar to truly grammatical and partly similar to truly ungrammatical sentences. Increased activation in the bilateral IFG was found for the overlap between truly ungrammatical sentences and grammatical norm violations as opposed to truly grammatical sentences. These brain areas, especially the Left IFG, are often associated with increased difficulties in grammatical processing (Embick et al., 2000; Friederici et al., 2006; Hagoort, 2005; Petersson et al., 2004; Snijders et al., 2009). This is rather surprising in the light of the linguistic view that grammatical norm violations are underlyingly grammatical. Our results suggest that language purists in fact partly process grammatical norm violations like truly ungrammatical sentences. This might indicate that for language purists grammatical norm violations are not part of their internal grammar. Yet, they do understand these constructions without any problems. The grammar of an adult speaker is usually thought of as a fully symmetrical system in which sentences that can be interpreted by the speaker will also be produced by them and vice versa (Hendriks, 2014). In fact, people may produce constructions that they simultaneously judge ungrammatical themselves (Asudeh, 2011). According to Ivanova, Pickering, McLean, Costa, and Branigan (2012) constructions that occur in everyday language, although claimed to be ungrammatical, can still be elicited by syntactic priming. Therefore, we do believe that grammatical norm violations are not truly ungrammatical, but they are not completely like regular grammatical sentences either, at least not for language purists who do not use these constructions themselves. That is to say, grammatical norm violations are compatible with the internal grammar of language purists, but there is clearly something about them that makes them 'difficult' to process, which is reflected in the IFG activation.

However, this need not be their grammaticality or their syntax. There is much evidence that the LIFG is not syntax specific (e.g. Hagoort, Baggio, \& Willems, 2009; Hagoort, Hald, Bastiaansen, \& Petersson, 2004), thus we cannot conclude that the elicited activation for grammatical norm violations in LIFG is due to basic syntactic difficulties. We favour a more domain-general perspective, which would state that, as grammatical norm violations will be internally corrected by the language purist, the LIFG activation is a result of increased unification (Hagoort, 2005) or cognitive control (Bornkessel-Schlesewsky, Grewe, \& Schlesewsky, 2012; Bornkessel-Schlesewsky \& Schlesewsky, 2012, 2013) processing. The present study seems to suggest that the LIFG activation is related to violations of expectations of grammatical input, rather than the ability to construct a basic syntactic representation (see e.g. Bornkessel-Schlesewsky \& Schlesewsky, 2013). Grammatical norm violations are comparable to garden-path sentences that are grammatical yet also elicit activation in the LIFG (den Ouden, Dickey, Anderson, \& Christianson, 2015).

Although language purists thus show overlap in their processing of grammatical norm violations and truly ungrammatical sentences, their processing of grammatical norm violations also overlapped with the processing of truly grammatical sentences. A decreased activation was found in the left mSFG and the left AG for truly ungrammatical sentences as compared to grammatical norm violations and grammatical sentences. Although the Angular Gyrus can lead to an increased activity in response to grammatical violations regarding word order (Embick et al., 2000), these brain areas typically play a role in semantic processing (Binder, Desai, Graves, \& Conant, 2009). More specifically, the Angular Gyrus (BA 39 ) is found to be involved in semantic integration (Binder et al., 2009; Hagoort et al., 2009; Seghier, 2013). These areas are usually involved when the interpretation can be integrated in conceptual memory (Binder et al., 2009; Seghier, 2013). People are able to come to a coherent semantic interpretation for both grammatical norm violations and truly grammatical sentences. Therefore these sentences can be semantically integrated perfectly well. However, for truly ungrammatical sentences it is hard to come to a coherent semantic interpretation, as these sentences do not find a match in conceptual memory. As a consequence, these sentences will not be integrated in conceptual memory, which leads to the decrease of activation in the LAG. Interestingly, the same pattern can be seen for social/semantic items: Increased activation in the LAG is observed for social norm violations and neutral sentences, which have a coherent semantic interpretation that can be integrated in conceptual memory, whereas for semantic violations no increased activation is found in this area - these sentences do not have a coherent semantic interpretation and therefore cannot be integrated in conceptual memory. The deactivation or absence of activation in the LAG for truly ungrammatical sentences and sentences containing a semantic anomaly suggests that for the grammatical and social norm violations and for the grammatical and neutral sentences people are able to extract a coherent semantic interpretation, whereas this is not the case for the linguistic violations (truly ungrammatical sentences and semantic violations).

The increased activation in the medial Superior Frontal Gyrus for grammatical norm violations and truly grammatical sentences as compared to truly ungrammatical sentences might tentatively be a reflection of perspective taking (Amodio \& Frith, 2006; Buckner, Andrews-Hanna, \& Schacter, 2008; Mason \& Just, 2006), 
that is hampered in the linguistically incorrect conditions. A similar larger activation in mSFG was again seen for social norm and correct sentences compared to the linguistic (semantic) violation.

In addition to the overlap between the processing of social norm violations and neutral sentences, specific effects were found for sentences describing a social norm violation. The medial Superior Frontal Gyrus is increasingly activated in response to social norm violations as opposed to neutral sentences. This is in line with previous literature in which violations of social norms are compared with normal behaviour (Berthoz et al., 2002) and in which socio-normative judgements are compared with grammatical judgements (Prehn et al., 2008).

Comparing the results of the grammatical norm violations to social norm violations suggests that grammatical norm violations are more linguistic than social in nature, since no specific effects were found for grammatical norm violations, whereas these effects were present for social norm violations. Also, the processing of grammatical norm violations partly overlapped with the processing of truly ungrammatical sentences, whereas this was not the case for social norm violations nor for semantically anomalous sentences. Yet, grammatical norm violations cannot be considered entirely equal to truly ungrammatical sentences, as the processing of grammatical norm violations overlapped with the processing of truly grammatical sentences as well. On the one hand, we found evidence for our hypothesis that grammatical norm violations are processed like grammatical sentences, in that both types of sentences can be interpreted and integrated with conceptual memory perfectly well. On the other hand, however, the processing of grammatical norm violations resembles that of truly ungrammatical sentences, possibly because both types of sentences are considered to be unacceptable for language purists.

Like garden-path sentences, grammatical norm violations elicit activation in the LIFG (den Ouden et al., 2015), but the difficulties can be resolved and a coherent semantic interpretation can be extracted, which results in increased activation in the AG (den Ouden et al., 2015). Truly ungrammatical sentences differ from grammatical norm violations (and garden-path sentences), in that truly ungrammatical sentences do not lead to a coherent semantic interpretation. Hence, no increased activation in the $A G$ is observed.

\section{Conclusion}

By means of this fMRI study, we sought to investigate the processing of grammatical norm violations in the brains of higheducated people who strongly disapprove of grammatical norm violations. We did not find any specific effects in the processing of grammatical norm violations, which might indicate that social cognition and basic emotions are not involved in the processing of these constructions, although this might also be due to task or age effects.

Yet, grammatical norm violations can be considered unique, since the processing of these constructions partly overlaps with the processing of grammatical sentences on the one hand, and partly with the processing of truly ungrammatical sentences on the other. The overlap between the processing of grammatical norm violations and grammatical sentences (in Left Angular Gyrus and $\mathrm{mSFG}$ ) can be explained by the fact that both types of sentences can be interpreted perfectly well, whereas this is not the case for truly ungrammatical sentences. The processing of grammatical norm violations and truly ungrammatical sentences might overlap in the IFG as both types of sentences violate expectations of grammatical input.

\section{Acknowledgements}

We are grateful to Vera van Mulken and Thijs Trompenaars for their help with the preparation of the experiment and we would like to thank Paul Gaalman for his support with the MRI scanner. We thank two anonymous reviewers for their helpful comments.

\section{Appendix A. Supplementary material}

Supplementary data associated with this article can be found, in the online version, at http://dx.doi.org/10.1016/j.bandl.2016.08. 006.

\section{References}

Aleman, A., \& Swart, M. (2008). Sex differences in neural activation to facial expressions denoting contempt and disgust. PLOS ONE, 3(11), e3622.

Amodio, D. M., \& Frith, C. D. (2006). Meeting of minds: The medial frontal cortex and social cognition. Nature Reviews Neuroscience, 7(4), 268-277.

Asudeh, A. (2011). Local grammaticality in syntactic production. In E. M. Bender \& J E. Arnold (Eds.), Language from a cognitive perspective. Stanford: CSLI.

Baayen, R. H., Piepenbrock, R., \& Gulikers, L. (1995). The CELEX lexical database (CDROM). Philadelphia, PA: Linguistic Data Consortium, University of Pennsylvania.

Barbiers, S., Bennis, H. J., de Vogelaer, G., Devos, M., \& van der Ham, M. H. (2005). Syntactische Atlas van de Nederlandse Dialecten/Syntactic atlas of the Dutch Dialects (Vol. I) Amsterdam: Amsterdam University Press.

Ben-Shachar, M., Hendler, T., Kahn, I., Ben-Bashat, D., \& Grodzinsky, Y. (2003). The neural reality of syntactic transformations: Evidence from functional magnetic resonance imaging. Psychological Science, 14(5), 433-440. Retrieved from <http://www.ncbi.nlm.nih.gov/pubmed/12930473>.

Ben-Shachar, M., Palti, D., \& Grodzinsky, Y. (2004). Neural correlates of syntactic movement: Converging evidence from two fMRI experiments. Neurolmage, 21 (4), 1320-1336.

Berthoz, S., Armony, J. L., Blair, R. J. R., \& Dolan, R. J. (2002). An fMRI study of intentional and unintentional (embarrassing) violations of social norms. Brain: A Journal of Neurology, 125(Pt 8), 1696-1708.

Binder, J. R., Desai, R. H., Graves, W. W., \& Conant, L. L. (2009). Where is the semantic system? A critical review and meta-analysis of 120 functional neuroimaging studies. Cerebral Cortex (New York, N.Y.: 1991), 19(12), 2767-2796.

Bock, K., \& Miller, C. A. (1991). Broken agreement. Cognitive Psychology, 23(1), 45-93.

Bornkessel-Schlesewsky, I., Grewe, T., \& Schlesewsky, M. (2012). Prominence vs. aboutness in sequencing: A functional distinction within the left inferior frontal gyrus. Brain and Language, 120(2), 96-107.

Bornkessel-Schlesewsky, I., \& Schlesewsky, M. (2012). Linguistic sequence processing and the prefrontal cortex. The Open Medical Imaging Journal, 6(1).

Bornkessel-Schlesewsky, I., \& Schlesewsky, M. (2013). Reconciling time, space and function: A new dorsal-ventral stream model of sentence comprehension. Brain and Language, 125(1), 60-76.

Buckner, R. L., Andrews-Hanna, J. R., \& Schacter, D. L. (2008). The brain's default network: Anatomy, function, and relevance to disease. Annals of the New York Academy of Sciences, 1124, 1-38.

Caplan, D., Alpert, N., Waters, G., \& Olivieri, A. (2000). Activation of Broca's area by syntactic processing under conditions of concurrent articulation. Human Brain Mapping, 9, 65-71.

Vos, H. de. (2015). The grammaticality of 'groter als'. A study using a sentence matching task. Unpublished report, Radboud Honours Academy. Radboud University Nijmegen.

den Ouden, D.-B., Dickey, M. W., Anderson, C., \& Christianson, K. (2015). Neural correlates of early-closure garden-path processing: Effects of prosody and plausibility. Quarterly Journal of Experimental Psychology, 0218(May), 1-24.

Duffield, N., Matsuo, a., \& Roberts, L. (2007). Acceptable ungrammaticality in sentence matching. Second Language Research, 23(2), 155-177.

Duffield, N., White, L., De Garavito, J. B., Montrul, S., \& Prévost, P. (2002). Clitic placement in L2 French: Evidence from sentence matching. Journal of Linguistics, 38(03), 487-525.

Embick, D., Marantz, a., Miyashita, Y., O’Neil, W., \& Sakai, K. L. (2000). A syntactic specialization for Broca's area. Proceedings of the National Academy of Sciences of the United States of America, 97(November), 6150-6154.

Evans, A. C., Collins, D. L., Mills, S. R., Brown, E. D., Kelly, R. L., \& Peters, T. M. (1993), 3D statistical neuroanatomical models from 305 MRI volumes. In 1993 IEEE conference record nuclear science symposium and medical imaging conference (pp. 1813-1817). IEEE.

Fedorenko, E., \& Thompson-Schill, S. L. (2014). Reworking the language network Trends in Cognitive Sciences, 18(3), 120-126.

Fiebach, C. J., Schlesewsky, M., Lohmann, G., von Cramon, D. Y., \& Friederici, A. D. (2005). Revisiting the role of Broca's area in sentence processing: Syntactic integration versus syntactic working memory. Human Brain Mapping, 24(2), 79-91.

Forman, S. D., Cohen, J. D., Fitzgerald, M., Eddy, W. F., Mintun, M. A., \& Noll, D. C. (1995). Improved assessment of significant activation in functional magnetic 
resonance imaging (fMRI): Use of a cluster-size threshold. Magnetic Resonance in Medicine: Official Journal of the Society of Magnetic Resonance in Medicine/ Society of Magnetic Resonance in Medicine, 33(5), 636-647.

Friederici, A. D. (2002). Towards a neural basis of auditory sentence processing. Trends in Cognitive Sciences, 6(2), 78-84.

Friederici, A. D., Fiebach, C. J., Schlesewsky, M., Bornkessel, I. D., \& von Cramon, D. Y. (2006). Processing linguistic complexity and grammaticality in the left frontal cortex. Cerebral Cortex, 16(12), 1709-1717.

Friederici, A. D., Pfeifer, E., \& Hahne, A. (1993). Event-related brain potentials during natural speech processing: Effects of semantic, morphological and syntactic violations. Brain Research. Cognitive Brain Research, 1(3), 183-192.

Griswold, M. a., Jakob, P. M., Heidemann, R. M., Nittka, M., Jellus, V., Wang, J., .. Haase, A. (2002). Generalized autocalibrating partially parallel acquisitions (GRAPPA). Magnetic Resonance in Medicine, 47, 1202-1210.

Gunning-Dixon, F. M., Gur, R. C., Perkins, A. C., Schroeder, L., Turner, T., Turetsky, B. I., ... Gur, R. E. (2003). Age-related differences in brain activation during emotional face processing. Neurobiology of Aging, 24(2), 285-295.

Hagoort, P. (2005). On Broca, brain, and binding: A new framework. Trends in Cognitive Sciences, 9(9), 416-423.

Hagoort, P. (2016). MUC (Memory, Unification, Control): A model on the neurobiology of language beyond single word processing. In Neurobiology of language (pp. 339-347). Elsevier.

Hagoort, P., Baggio, G., \& Willems, R. M. (2009). Semantic unification. In M. S. Gazzaniga (Ed.), The cognitive neurosciences (4th ed., pp. 819-836). Cambridge, MA: MIT Press.

Hagoort, P., Hald, L., Bastiaansen, M., \& Petersson, K. M. (2004). Integration of word meaning and world knowledge in language comprehension. Science, 304(5669), 438-441.

Hawkins, J. A. (2004). Efficiency and complexity in grammars. Oxford, UK: Oxford University Press.

Hendriks, P. (2014). Asymmetries between language production and comprehension. Dordrecht: Springer.

Hubers, F., \& de Hoop, H. (2013). The effect of prescriptivism on comparative markers in spoken Dutch. Linguistics in the Netherlands, 30, 89-101. http://dx. doi.org/10.1075/avt.30.07hub.

Iidaka, T., Okada, T., Murata, T., Omori, M., Kosaka, H., Sadato, N., \& Yonekura, Y. (2002). Age-related differences in the medial temporal lobe responses to emotional faces as revealed by fMRI. Hippocampus, 12(3), 352-362. http://dx. doi.org/10.1002/hipo.1113.

Ivanova, I., Pickering, M. J., McLean, J. F., Costa, A., \& Branigan, H. P. (2012). How do people produce ungrammatical utterances? Journal of Memory and Language, 67 (3), 355-370.

Just, M. A., Carpenter, P. A., \& Woolley, J. D. (1982). Paradigms and processes in reading comprehension. Journal of Experimental Psychology: General, 111(2), $228-238$.

Langner, O., Dotsch, R., Bijlstra, G., Wigboldus, D. H. J., Hawk, S. T., \& van Knippenberg, A. (2010). Presentation and validation of the Radboud Faces Database. Cognition E' Emotion, 24(8), 1377-1388.

Lasnik, H., \& Sobin, N. (2000). The who/whom puzzle: On the preservation of an archaic feature. Natural Language and Linguistic Theory, 18, 343-371.
Mai, J. K., Assheuer, J., \& Paxinos, G. (2004). Atlas of the human brain (2nd ed.). London: Elsevier Academic Press.

Mason, R. A., \& Just, M. A. (2006). Neuroimaging contributions to the understanding of discourse processes. In M. Traxler \& M. A. Gernsbacher (Eds.), Handbook of psycholinguistics (pp. 765-799). Amsterdam: Elsevier.

Mather, M., Canli, T., English, T., Whitfield, S., Wais, P., Gabrieli, J. D. E., ... Ochsner, K. (2004). Amygdala responses to emotionally valenced stimuli in older and younger adults. Psychological Science, 15(4), 259-263.

Mitchell, D. C. (2004). On-line methods in language processing: Introduction and historical review. In M. Carreiras \& C. J. Clifton (Eds.), The on-line study of sentence comprehension: Eyetracking, ERPs and beyond (pp. 15-32). New York, NY: Psychology Press.

Oostdijk, N. H. J. (2000). The Spoken Dutch Corpus Project. ELRA Newsletter, 5(2), 4-8.

Osterhout, L., \& Holcomb, P. J. (1992). Event-related brain potentials elicited by syntactic anomaly. Journal of Memory and Language, 31(6), 785-806.

Petersson, K. M., Forkstam, C., \& Ingvar, M. (2004). Artificial syntactic violations activate Broca's region. Cognitive Science, 28(3), 383-407.

Pinker, S. (1994). The language instinct. New York, NY: Harper Perennial Modern Classics.

Prehn, K., Wartenburger, I., Mériau, K., Scheibe, C., Goodenough, O. R., Villringer, A., ... Heekeren, H. R. (2008). Individual differences in moral judgment competence influence neural correlates of socio-normative judgments. Social Cognitive and Affective Neuroscience, 3(1), 33-46.

Rorden, C., Karnath, H.-O., \& Bonilha, L. (2007). Improving lesion-symptom mapping. Journal of Cognitive Neuroscience, 19(7), 1081-1088.

Sambataro, F., Dimalta, S., Di Giorgio, A., Taurisano, P., Blasi, G., Scarabino, T., ... Bertolino, A. (2006). Preferential responses in amygdala and insula during presentation of facial contempt and disgust. European Journal of Neuroscience, 24 (8), 2355-2362.

Santi, A., \& Grodzinsky, Y. (2007). Working memory and syntax interact in Broca's area. NeuroImage, 37(1), 8-17.

Seghier, M. L. (2013). The angular gyrus: Multiple functions and multiple subdivisions. The Neuroscientist: A Review Journal Bringing Neurobiology, Neurology and Psychiatry, 19(1), 43-61.

Snijders, T. M., Vosse, T., Kempen, G., Van Berkum, J. J. a., Petersson, K. M., \& Hagoort, P. (2009). Retrieval and unification of syntactic structure in sentence comprehension: An FMRI study using word-category ambiguity. Cerebral Cortex (New York, N.Y.: 1991), 19(7), 1493-1503.

Spitzer, M., Fischbacher, U., Herrnberger, B., Grön, G., \& Fehr, E. (2007). The neural signature of social norm compliance. Neuron, 56(1), 185-196.

Thompson-Schill, S. L. (2005). Dissecting the language organ: A new look the role of Broca's area in language processing. In A. Cutler (Ed.), Twenty-first Century psycholinguistics: Four cornerstones. Mahwah (NJ): Lawrence Erlbaum Press.

van Bergen, G., Stoop, W., Vogels, J., \& de Hoop, H. (2011). Leve hun! Waarom hun nog steeds hun zeggen. Nederlandse Taalkunde, 16(1), 2-29.

van Casteren, M., \& Davis, M. H. (2006). Mix, a program for pseudorandomization. Behavior Research Methods, 38(4), 584-589.

Veenstra, A. (2014). Semantic and syntactic constraints on the production of subjectverb agreement. Radboud University Nijmegen. 